\title{
Lokalisasi Jarak dan Sudut Pembacaan Kartu Radio Frequecy Identification (RFID)
}

\author{
Anwar Mujadin $^{1}$, Dwi Astharini² \\ ${ }^{1,2}$ Program Studi Teknik Elektro, Fakultas Sains dan Teknologi, Komplek Masjid Agung Al Azhar \\ Kebayotan Baru \\ Jakarta Selatan , Kode Pos 12110
}

Penulis untuk Korespondensi/E-mail: amujadin@uai.ac.id

\begin{abstract}
Abstrak - Teknis pembacaan kartu RFID (tag) dimana pembaca kartunya (card reader) diletakan dekat permukaan logam akan memiliki pelemahan sensitivitas sinyal penerimaan radio frekuensi yang cukup significan. Dari hasil percobaan membuktikan bahwa received signal strength index (RSSI) akan berkurang $14 \mathrm{dBm}$ bila reader diletakan dekat dengan permukaan logam. RSSI adalah sebuah pendekatan cermat untuk optimasi jarak dan sudut antara pemancar (tag) dan penerima (reader). Dari hasil percobaan menunjukan pula bahwa bukan hanya jarak, sudut maupun logam yang mempengaruhi besaran nilai RSSI namun besaran kendali daya pemancar (reader) agar tag aktif dalam jarak dan sudut yang telah dilokalisai. Dalam paper ini akan dijelaskan dengan singkat hubungan antara kendali daya dan RSSI dalam mengaktifasi kartu RFID (tag).
\end{abstract}

Kata Kunci - RFID received signal strength index, RFID Sensitivity reading tag

Abstract - RFID card (tag) and card reader are placed near metal surfaces, will be have attenation sensititivity of receiver signal radio frequency significantly. The result of exsperiment shown that distance between the tag and the reader using the received signal strength index (RSSI) will be reduce by $14 \mathrm{dBm}$ from the beginning when RFID card reader placed near metal surface. RSSI is an careful approach to optimation the distance between a sender and a receiver. The our experiments shown that power control results are more stable and accurate than RSSI results. In this paper, will be explain briefly the relationship between power control and RSSI in activates the RFID card (tag).

Keywords - RFID received signal strength index, RFID Sensitivity reading tag

\section{PENDAHULUAN}

$\mathrm{M}$ ata kuliah embedded system dosen mengajarkan kepada mahasiswanya pada perancangan perangkat keras seperti layout electronic schematic dan printed circuit board (PCB). Dilanjutkan dengan mengajarkan mikrokontroler arsitektur, mikrokontroler programming, perakitan dan wiring. Kemudian dimplementasikan sesuai dengan kebutuhan pengguna (manusia). Implementasi mata kuliah embedded system harus spesifik, tepat sasaran tentunya dengan cost yang cukup murah. Pada saat ini banyak vendor yang menawarkan modul penunjang pengajaran sistem embedded ini. Namun, selain harganya mahal modul ini umumnya sulit untuk diperbaiki. Padahal dengan ide kreatif, modul pengajaran embedded sytem ini dapat dibuat dari komponen lokal dengan disain murah, mudah dirawat dan diperbaiki. Pada penelitian ini telah berhasil dikembangkan sebuah prototipe sebagai penunjang mata kuliah embedded system. Prototipe berbentuk model doorlock berbasis kartu RFID. Hasil produk prototipe diperlihatkan dalam dua sisi seperti yang terlihat pada Gambar 1 berikut. 


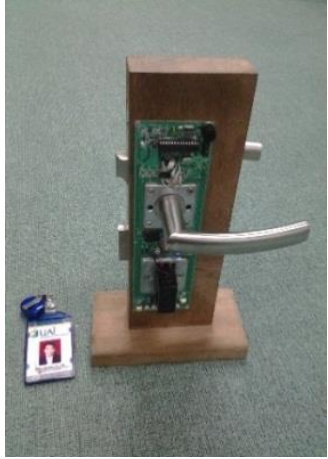

(a)

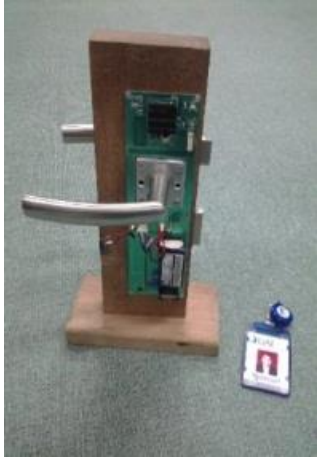

(b)
Gambar 1. Hasil produk prototipe diperlihatkan dalam 2 posisi (a) posisi indoor (b) posisi outdoor

Dari Gambar 1 (bagian outdoor), bagian paling atas terlihat kotak hitam berukuran $26 \mathrm{~mm} \times 25$ $\mathrm{mm} \times 6 \mathrm{~mm}$ yang merupakan RFID card reader type ID-12LA produk buatan Innovations. Sedangkan bagian paling bawah terlihan baterai Hippo 12V/850mA. Pada bagian (indoor), terlihat paling atas adalah mikrokontroler ATMega8, sensor sentuh (gagang pintu indoor) dan gear box motor DC untuk menggerakan grendel kunci.

Dibagian outdoor, ketika tag didekatkan pada reader, reader akan membaca ID kemudian disampaikan lewat interupsi serial ke mikrokontroler. Bila ID tag sama dengan data base terprogram, mikrokontroler akan segera mengendalikan gear box dc motor untuk menggerakan grandel pada posisi unlock. Sedangkan pada bagian indoor, cukup dengan menekan gagang kunci (terdapat sensor sentuh), grandel pintu dapat dibuka tanpa kartu RFID.

Prototipe ini mampu mengembangkan imajinasi mahasiswa untuk merilis sebuah pemograman implementasi dalam mata kuliah embedded system.

Dari Gambar 1, terlihat main board prototipe belum dikemas dengan wadah (casing). Rencana casing akan dibuat dari bahan logam alumunium.

Hasil ekperimen ternyata casing logam menyebabkan sensitivitas pembacaan tag menjadi berkurang. Card reader tentunya harus tertanam dengan main board, dan harus menyembul keluar dari area logam (dilubangi).

\section{TINJAUAN PUSTAKA}

\section{Radio Frequency Identification (RFID)}

RFID adalah suatu teknologi yang menggunakan frekuensi radio untuk mengidentifikasi suatu divais. Sistem RFID terdiri dari atas dua komponen utama, yaitu tags dan reader. mekanisme kerja dalam sebuah sistem RFID diperlihatkan pada Gambar 2 [1].

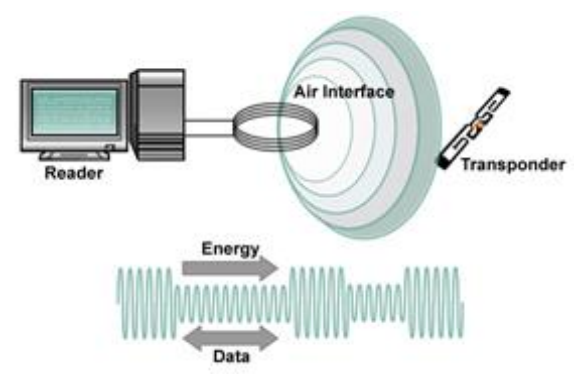

Gambar 2. Mekanisme kerja sebuah sistem RFID[1]

Reader akan mengeluarkan frekuensi radio $125 \mathrm{KHz}$, energi gelombang elektromagnetik akan mengaktifkan chip transponder yang ada didalam tag (ada sumber daya). Reader akan melakukan scanning terhadap data yang tersimpan dalam tags (kartu). Tag sering disebut juga transponder atau transceiver. Dalam tag ini berisi antena untuk menangkap sinyal dari reader. Tranceiver data RFID menggunakan amplitude shift keying (ASK) [2]. Pada Gambar 3 diperlihatkan beberapa modulator digital.

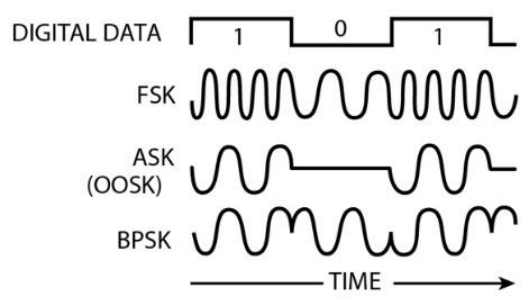

Gambar 3. Beberapa jenis modulator digital [2].

Data output tag serial mempunyai 128 bit. Terdiri dari 11 bit header, 64 bit data, 16 bit CRC, 24 bit extension bits, dan 13 bit framing bits. Komposisi bit ini sesuai dengan protokol ISO11785.

Modul RFID reader ID-12A akan mengeluarkan data tag maupun stregth signal melaui komunikasi serial RS232 protokol dalam format ASCII, yang bisa dibaca oleh 
baik oleh mikrokontroler maupun personal computer [3].

Pada Gambar 4. Diperlihatkan bentuk modul ID-12LA dan konfigurasi pin keluarannya [3].

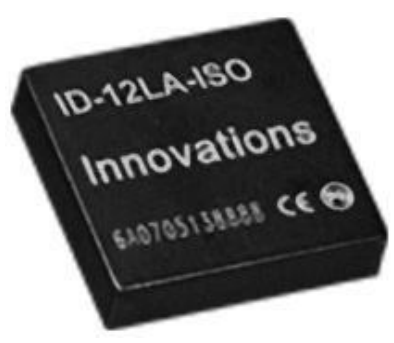

a.

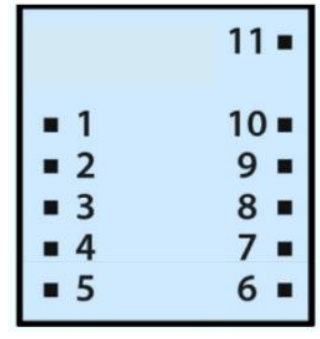

b.

Gambar 4. (a) Bentuk modul reader RFID

(a) Konfigurasi pin keluaran [3].

Sesuai dengan Gambar 4. Deskripsi dari konfigurasi pin keluaran modul reader ID12LA dijelaskan pada Tabel 1[3].

Tabel 1. Deskripsi konfigurasi pin keluaran modul reader ID-12LA [3]

\begin{tabular}{clc}
\hline Pin \# & Description & ASCII \\
\hline Pin 1 & Zero Volts & GND 0V \\
Pin 2 & Strap to +5V & Reset Bar \\
Pin 3 & DNC & Antenna \\
Pin 4 & DNC & Antenna \\
Pin 5 & Card Present & No function \\
Pin 6 & Tag in Range & Tag in Range \\
& Format Selector & Strap to GND \\
Pin 7 & $(+/-)$ & CMOS \\
Pin 8 & Data 1 & TTL Data \\
Pin 9 & Data 0 & Beeper / \\
Pin 10 & 3 kHz Logic & LED \\
Pin 11 & Voltage Supply & $+5 \mathrm{~V}$ \\
\hline
\end{tabular}

Modul ID-12LA perlu dirakit dengan komponen elektronik penunjang seperti yang diperlihatkan pada Gambar 5 [3].

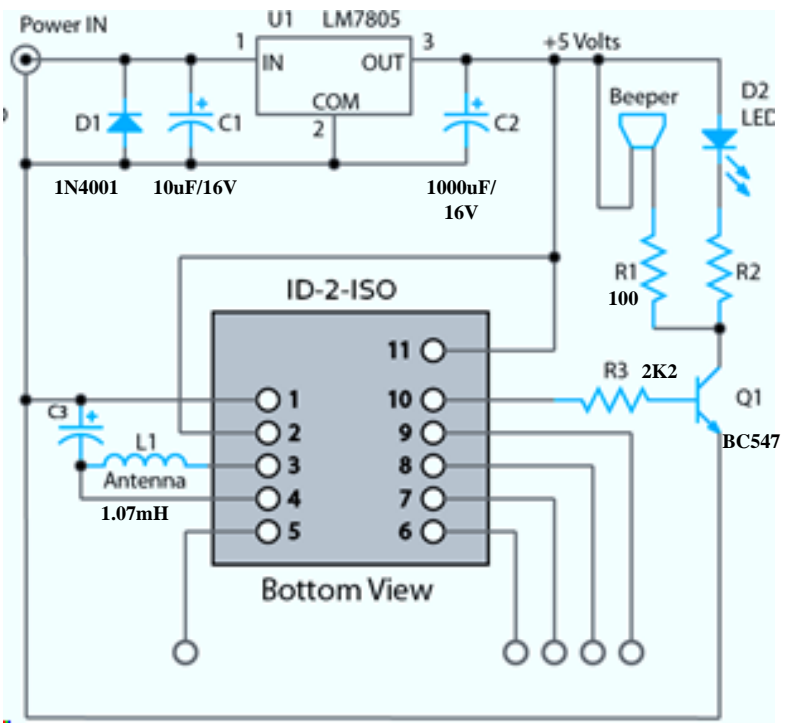

Gambar 5. Komponen elektronika penunjang modul reader ID-12LA [3].

\section{Received Signal Strength Index (RSSI)}

RSSI adalah nilai untuk menentukan sebuah indikasi relatif dari kualitas unit sensor dan titik akses yang terhubung dalam jaringan nirkabel. RSSI merupakan alat untuk menentukan kualitas hubungan dalam tranceiver komunikasi data nirkabel.

Kekuatan sinyal adalah dasar sejumlah factor, termasuk daya keluaran dari pemancar (kekuatan sinyal asli). Sensitivitas dari penerima ( bagaimana divais penerima "mendengar" sinyal lemah). Penguatan antena memberi peranan penting dalam menentukan kekuatan sinyal. Kekuatan sinyal diekpresikan dalam $\mathrm{dBm}$. Di karenakan terjadi pelemahan sinyal oleh lingkungan disekitarnya, maka RSSI dinyatakan dalam bilangan negatif. Semakin dekat tag dengan reader, maka besaran RSSI dari bilangan negatif mendekati nol. Namun sebaliknya bila tag makin menjauh dari reader, nilai RSSI bilangan negatifnya semakin besar [4].

Pada Tabel. 2 diperlihatkan kategori kekuatan sinyal RSSI [4]

Tabel 2. Kategori kekuatan sinyal RSSI [4].

\begin{tabular}{cc}
\hline RSSI Range Signal & Quality \\
\hline Better than $-40 \mathrm{dBm}$ & Exceptional \\
$-40 \mathrm{dBm}$ to $-55 \mathrm{dBm}$ & Very Good \\
$-55 \mathrm{dBm}$ to $-70 \mathrm{dBm}$ & Good \\
$-70 \mathrm{dBm}$ to $-80 \mathrm{dBm}$ & Marginal \\
$-80 \mathrm{dBm}$ and beyond & Intermittent \\
\hline
\end{tabular}


Selain besaran nilai RSSI dipengaruhi oleh jarak dan sudut penempatan tag terhadap reader. Nilai RSSI juga dipengaruhi oleh lingkungan disekitarnya [5][6][7].

\section{METODE PENELITIAN}

Kerangka fikir dari metode penilitian:

a. Mencari korelasi penempatan jarak tag, sudut tag maupun penggangu di area sistem RFID, terhadap nilai RSSI.

b.Pengambilan data hasil ekperimen, optimasi validasi data tag. Pada jarak konstan terhadap variasi sudut. Dilanjutkan pada sudut konstan terhadap variasi jarak.

c.Pengambilan data hasil eksperimen, mengukur kekuatan sinyal RSSI pada jarak konstan terhadap variasi sudut. Dilanjutkan pada sudut konstan terhadap variasi jarak.

\section{HASIL DAN PEMBAHASAN}

Validasi data adalah menentukan tag dapat dibaca atau tidak oleh reader. Selama reader mampu membaca pada lokalisasi jarak dan sudut tag, maka

Kondisi ini disebut valid.

Pada Gambar 6. Diperlihatkan ilustrasi validasi data tag terhadap jarak dan sudut

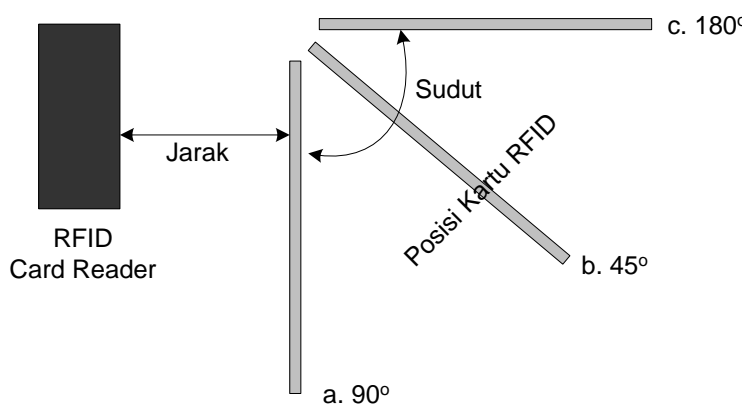

Gambar 6. Ilustrasi validasi data tag terhadap jarak dan sudut.
Data hasil eksperimen diperlihatkan pada Tabel 3.

Tabel 3. Data hasil eksperimen validasi data tag terhadap jarak dan sudut.

\begin{tabular}{|c|c|c|}
\hline $\begin{array}{c}\text { Jarak } \\
(\mathrm{cm})\end{array}$ & $\begin{array}{c}\text { Sudut } \\
\text { (Derajat) }\end{array}$ & Sensitifitas \\
\hline 5 & 90 & Terbaca \\
\hline 10 & 90 & Terbaca \\
\hline 15 & 90 & Terbaca \\
\hline 20 & 90 & $\begin{array}{c}\text { Tidak } \\
\text { Terbaca }\end{array}$ \\
\hline 5 & 45 & Terbaca \\
\hline 10 & 45 & $\begin{array}{c}\text { Tidak } \\
\text { Terbaca }\end{array}$ \\
\hline 15 & 45 & $\begin{array}{l}\text { Tidak } \\
\text { Terbaca }\end{array}$ \\
\hline 20 & 45 & $\begin{array}{l}\text { Tidak } \\
\text { Terbaca }\end{array}$ \\
\hline 5 & 180 & $\begin{array}{c}\text { Tidak } \\
\text { Terbaca }\end{array}$ \\
\hline 10 & 180 & $\begin{array}{c}\text { Tidak } \\
\text { Terbaca }\end{array}$ \\
\hline 15 & 180 & $\begin{array}{c}\text { Tidak } \\
\text { Terbaca }\end{array}$ \\
\hline 20 & 180 & $\begin{array}{c}\text { Tidak } \\
\text { Terbaca }\end{array}$ \\
\hline
\end{tabular}

Pada Tabel 3, terlihat bahwa tag akan diidentifikasi dengan mudah oleh reader bila tag diletakan pada posisi jarak berturut-turut 5 $\mathrm{cm}, 10 \mathrm{~cm}$, dan $15 \mathrm{~cm}$ tegak lurus $\left(90^{\circ}\right)$ terhadap modul reader. Posisi tag pada sudut $45^{\circ}$ mampu dibaca asalkan lokalisasi tag sedekat mungkin dengan reader.

Hampir semua kartu RFID pada sudut $180^{\circ}$ tidak mampu dibaca oleh modul RFID reader walaupun jaraknya sangat dekat sekali, ini disebabkan karena antena pada tag tidak mampu menerima sinyal radio $125 \mathrm{KHz}$ dari modul reader, karena medan magnet menjadi lebih besar dibandingkan dengan medan listrik (tidak ada supply energi).

Selanjutnya pengujian RSSI, reader dikonfigurasikan pada tag in range, kekuatan sinyal transfonder diukur oleh prosesor dalam modul ID-12LA kemudian dikeluarkan melalui serial komunikasi. Data RSSI ditampilkan dalam hyperterminal windows. Data RSSI dikumpulkan untuk setiap perubahan jarak dan sudut tag terhadap reader. Tag dialokasikan pada sudut $90^{\circ}$ dan $45^{\circ}$ terhadap reader. 
Pengujian diulang pada area logam maupun tanpa logam dengan ketentuan validasi data tag dapat dibaca.

Pada Gambar 7 diperlihatkan grafik hasil pengamatan RSSI terhadap jarak tag dan reader pada sudut $90^{\circ}$.

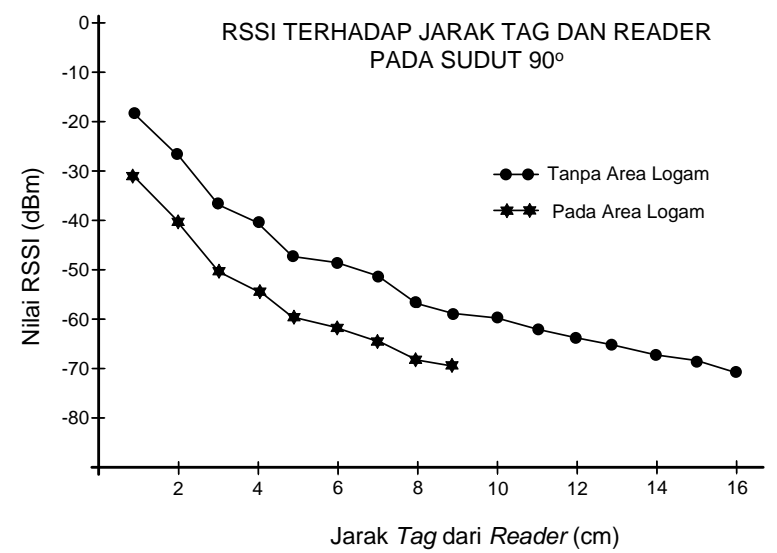

Gambar 7. Grafik hasil pengamatan RSSI terhadap jarak tag dan reader pada sudut $90^{\circ}$

Pada Gambar 8 diperlihatkan grafik hasil pengamatan RSSI terhadap jarak tag dan reader pada sudut $45^{\circ}$.

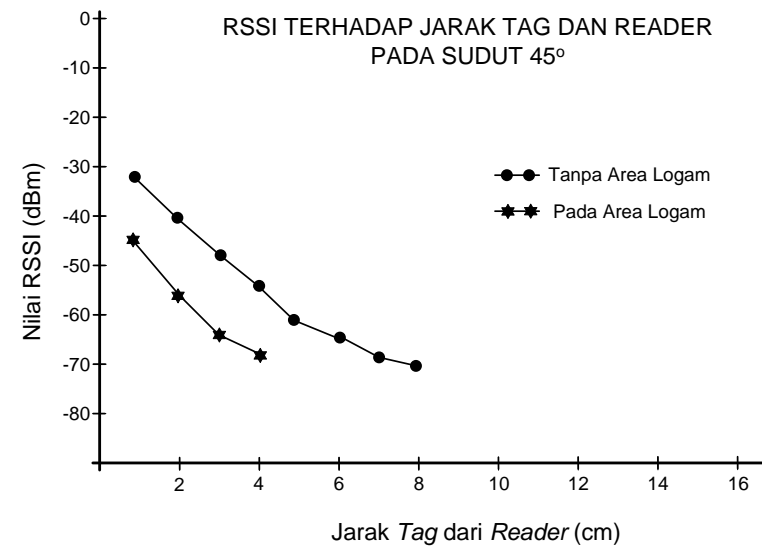

Gambar 8. Grafik hasil pengamatan RSSI terhadap jarak tag dan reader pada sudut $45^{\circ}$.

Dari Gambar 7 menunjukan, nilai RSSI terhadap variasi jarak tag dan reader pada sudut $90^{\circ}$ tag saat diuji pada area tanpa logam didaerah reader memiliki sensitivitas pembaacan tag (RSSI) pada jangkauan -18 $\mathrm{dBm}$ sampai $-69 \mathrm{dBm}$. Kemudian pada saat reader dipasang casing logam, sensitivitas pembacaan tag (RSSI) turun pada jangkauan $32 \mathrm{dBm}$ sampai $-69 \mathrm{dBm}$. Artinya terjadi penurunan sensitivitas RSSI sebesar :

$$
-18 \mathrm{dBm}-(-32 \mathrm{dBm})=14 \mathrm{dBm}
$$

dan terjadi penurunan sensitivitas maka jarak validasi tag menjadi berkurang, semula $16 \mathrm{~cm}$ menjadi $9 \mathrm{~cm}$.

Dari Gambar 8 menunjukan, nilai RSSI terhadap variasi jarak tag dan reader pada sudut $45^{\circ}$ tag saat diuji pada area tanpa logam didaerah reader memiliki memiliki sensitivitas pembaacan tag (RSSI) pada jangkauan -32 $\mathrm{dBm}$ sampai $-69 \mathrm{dBm}$. Kemudian pada saat reader dipasang casing logam, sensitivitas pembacaan tag (RSSI) turun pada jangkauan $45 \mathrm{dBm}$ sampai $-69 \mathrm{dBm}$. Artinya terjadi penurunan sensitivitas RSSI sebesar :

$$
-32 \mathrm{dBm}-(-45 \mathrm{dBm})=13 \mathrm{dBm}
$$

dan terjadi penurunan sensitivitas jarak validasi tag semula $8 \mathrm{~cm}$ menjadi $4 \mathrm{~cm}$.

\section{KESIMPULAN}

Dari hasil ekperimen ditunjukan bahwa validasi tag

Pada lokalisasi sudut $90^{\circ}$ (tag dan reader saling tegak lurus) masih bisa dibaca pada jangkauan jarak dibawah $15 \mathrm{~cm}$. Pada lokalisai sudut $45^{\circ}$, sensitivitas validasi tag turun dan hanya mampu dibaca pada jarak $5 \mathrm{~cm}$.

Ditunjukan juga pada lokalisasi sudut $180^{\circ}$ tag sama sekali tidak terbaca oleh reader ini disebabkan karena antena pada tag tidak mampu menerima sinyal radio $125 \mathrm{KHz}$ dari modul reader, karena medan magnet menjadi lebih besar dibandingkan dengan medan listrik (tidak ada supply energi).

Ditunjukan pula nilai nilai received signal strength index (RSSI) akan menurun sebesar 14 $\mathrm{dBm}$, bila di area reader ditempatkan logam alumunium, ini terjadi karena logam alumunium menyerap energi radiasi gelombang elektromagnetik tranceiver tag, sehingga untuk tambahan energi dari gelombang RF dari reader, lokalisasi tag harus sedekat mungkin 
dengan reader atau minimal pada jarak dibawah $9 \mathrm{~cm}$.

Modul ID-12LA RFID reader bekerja pada frekuensi RF $125 \mathrm{KHz}$, pada jangkauan tag dibawah $15 \mathrm{~cm}$, modul ini memiliki sensitifitas pembacaan tag (RSSI) dari - $18 \mathrm{dBm}$ sampai $69 \mathrm{dBm}$.

Ditunjukan pula lokalisasi jarak dan sudut tag terhadap reader, sangat penting perananya terutama untuk menentukan RSSI tervalidasi.

\section{UCAPAN TERIMA KASIH}

PENELITIAN INI DIDUKUNG OLEH PRODI ELEKTRO FAKULTAS SAINS DAN TEKNOLOGI UNIVERSITAS AL AZHAR INDONESIA, RESEARCH GRANT 20142015 SPK LP2M UAI NO.046/SPK/A01/UAI/X/2014

\section{DAFTAR ACUAN/PUSTAKA}

[1] S. Preradovic, N. C. Karmakar, and I. Balbin, "RFID transponders," IEEE MicrowaveMagazine, vol. 9, no. 5, pp. 90-103, 2008.

[2] K. Finkenzeller, RFID Handbook: Fundamentals and Applications in Contactless Smart Cards, Radio Frequency Identification and Near-Field Communication, Wiley, 2003.
[3] Innovation corp, ID-3/12/20LA-ISO RFID Reader Modules for ISO11785 FDX tags

Datasheet,http://www.idinnovations.com/ download.html,2015.(Diakses pada 2 Februari 2015).

[4] WV18, Veris Aerospond Wireless Sensors, Received Signal Strength Indicator (RSSI) http://www.wv18.com/download.html, 2013. (Diakses pada 3 Maret 2015).

[5] S. Azzouzi, M. Cremer, U. Dettmar, R. Kronberger, and T. Knie, "New measurement results for the localization of UHF RFID transponders using an Angle of Arrival (AoA) approach," in Proceedings of the 5th IEEE International Conference on RFID (RFID '11), pp. 91-97, April 2011.

[6] R.De Silva and P.Gonc,alves, "Enhancing the efficiency of active RFID-based indoor location systems," in proceedings of the IEEE Wireless Communications and Networking Conference (WCNC '09), April 2009.

[7] K. Finkenzeller, RFID Handbook: Fundamentals and Applications in Contactless Smart Cards, Radio Frequency Identification and Near-Field Communication, Wiley, 2003. 